\title{
DEVELOPMENT AND EVALUATION OF BILAYERED GASTRO-RETENTIVE TABLET CONTAINING METFORMINHCL SR AND PIOGLITAZONEHCL IR
}

\author{
*Vyas Jigar, Upadhyay Tulsi, Vyas Harsh, Dhameliya Pankit, Thakkar Nirali \\ Sigma Institute of pharmacy, At: Bakrol, Ajwa-Nimeta Road, Ta: Waghodiya, Dist: Vadodara. Pin: 390019
}

*Corrresponding Author's Email: drjrvyas@yahoo.co.in

\begin{abstract}
:
To get advantage of novel drug delivery in treatment of diabetes mellitus is centered aim of this work.Bi-layered gastroretentive tablet containing Metformin $\mathrm{HCl}$ and Pioglitazone $\mathrm{HCl}$ for treatment of type-II diabetes mellitus has been formulated . To make the system more effective, combination of immediate layer, PioglitazoneHCl $15 \mathrm{mg}$ and sustained release layer of Metformin $\mathrm{HCl} 500 \mathrm{mg}$ were prepared. The core tablet of Metformin $\mathrm{HCl}$ was prepared by using different swellable polymers like HPMC E15, HPMC K100 and carbopol by wet granulation method and evaluated for swelling index, total floating time and floating lag time. In vitro release studies were carried out with $0.1 \mathrm{~N} \mathrm{HCl}$ using USP dissolution apparatus 2 (paddle). Tablet thus formulated using HPMC K100M and E15 provided sustained release of Metformin HCl over a period of 10 hours. The immediate release layer of Pioglitazone $\mathrm{HCl}$ was prepared by using crosspovidone, a super disintegrant by direct compression method and evaluated for disintegration time and dissolution also. Then bilayered tablet was prepared with the selected core tablet batch of MetforminHCl followed by compression coating with the selected immediate release layer of PioglitazoneHCl. The present study concluded that bilayered tablet can be a good way to treat diabetic patients with combination therapy.

Keywords: bilayered tablet, diabetes, sustained release, immediate release
\end{abstract}

\section{INTRODUCTION:}

To get sustained release of the drug is aimed to decrease the dose and dosing frequency and so its side effects. Sustained-release formulations may be administered once or twice daily ${ }^{1}$. The multilayered tablet concept has been long utilized to develop sustained release formulations. Such a tablet has a fast releasing layer and may contain bior triple layers to sustain the drug release. The pharmacokinetic advantage relies on the fact that drug release from fast releasing granules leads to a sudden rise in the blood concentration. However, the blood level is maintained at steady state as the drug is released from the sustaining granules. Among the different polymers, Eudragit and Hydroxypropylmethylcellulose have been used successfully to obtain appropriate sustained release matrix formulations.

Metformin is an antihyperglycemic agent, which improves glucose tolerance in patients with type 2 diabetes, lowering both basal and postprandial plasma glucose. Metformin is not chemically or pharmacologically related to any other classes of oral antihyperglycemic agents. Metformin decreases hepatic glucose production, decreases intestinal absorption of glucose, and improves insulin sensitivity by increasing peripheral glucose uptake and utilization. The drug also has relatively short plasma elimination half life of 1.5 to 4.5 hours $^{7,8}$. So SR products are needed for metformin to prolong its duration of action and improve patient compliance ${ }^{2,3}$.

Pioglitazone, a member of the drug group known as the thiazolidinediones or "insulin sensitizers", is not chemically or functionally related to the alpha-glucosidase inhibitors, the biguanides, or the sulfonylureas. Pioglitazone targets insulin resistance and, hence, is used alone or in combination with insulin, metformin, or asulfonylurea as an antidiabetic agent. pioglitazone both enhances tissue sensitivity to insulin and reduces hepatic gluconeogenesis. Thus, insulin resistance associated with type 2 diabetes mellitus is improved without an increase in insulin secretion by pancreatic $\beta$ cells.

\section{MATERIAL}

MetforminHCl and pioglitazone $\mathrm{HCl}$ were provided as gift sample Bharat PrenteralsLtd. Baroda,India. Hydroxypropylmethylcellulosee 15, hydroxypropylmethylcelluloseK100, carbopo1934, ethylcellulose, PVPK30, microcrystallinecellulose, sodium bicarbonate, citric acid, magnesium stearate and talc of analytical grade were purchased from National Chemicals, Mumbai. Isopropyl alcohol of analytical grade was purchased from Sigma Eldrich, Mumbai and used without any further purification

\section{METHODS}

Preparation of bilayered tablet: Bilayer tablet of MetforminHCl and Pioglitazine was developed in three different stages. Sustained release layer of MetforminHCl was prepared by wet granulation using solution of PVPK30 in isopropyl alcohol and immediate release layer of PioglitazoneHCl was optimized separately by direct compression technique. After optimization of individual layers, the bilayer tablet was prepared where immediate release layer was compression coated on optimized tablet of MetforminHCl.

Swelling index: The swelling index of tablets was determined in $0.1 \mathrm{~N} \mathrm{HCl}(\mathrm{pH} 1.2)$ at room temperature. The swollen weight of the tablet was determined at predefined time intervals over a period of $10 \mathrm{~h}$. The swelling index (SI), expressed as a percentage, and was calculated from the following equation $S I=\{(M t-M o) / M o\} X 100$; Where, 
$\mathrm{SI}=$ Swelling index, $\mathrm{Mt}=$ Weight of tablet at time ' $\mathrm{t}$ ' and Mo $=$ Weight of tablet at time ' $\mathrm{t}=0$ '.

In-vitro buoyancy studies: In-vitro buoyancy studies were performed for all the formulations as per the method described by Rosa et al. The randomly selected tablets from each formulation were kept in a 100ml beaker containing simulated gastric fluid, $\mathrm{pH} 1.2$ as per USP. The time taken for the tablet to rise to the surface and float was taken as floating lag time (FLT). The duration of time the dosage form constantly remained on the surface of medium was determined as the total floating time (TFT).

Release rate study: The release rate of MetforminHCl from floating tablets was determined USP dissolution testing apparatus type I (Basket method) and that of Pioglitazone $\mathrm{HCl}$ in USP dissolution testing apparatus type II. The dissolution test was performed using $900 \mathrm{ml}$ of $0.1 \mathrm{~N}$ hydrochloric acid, at $37 \pm 0.5^{\circ} \mathrm{C}$ and 50rpm. A sample $(5 \mathrm{ml})$ of the solution was withdrawn from the dissolution apparatus hourly and the samples were replaced with fresh dissolution medium. The samples were filtered through a $0.45 \mu$ membrane filter and diluted to a suitable concentration with $0.1 \mathrm{~N}$ hydrochloric acid. Absorbance of these solutions was measured at 232nm (for metforminHCl) and 268nm (for pioglitazone $\mathrm{HCl}$ ) using a UV/Visible spectrophotometer. The percentage drug release was plotted against time to determine the release profile

\section{RESULTS AND DISCUSSION:}

All the formulations given in table 1 and 3 were formulated.Once daily dosage form of sustained release MetforminHCl and immediate release Pioglitazone $\mathrm{HCl}$ tablets were formed they were evaluated for various physical properties individualy and the values are shown in the table 2 and 4 respectively. As swlling polymers are used to sustain the release swelling indexes ${ }^{6}$ were obtained for $10 \mathrm{hrs}$ and their results are given in table 2.Figure 1 and 2 shows the dissolution profile of MetforminHCl sustained release tablets and Pioglitazone $\mathrm{HCl}$ immediate release tablet.

Table 1: Formulation table of MetforminHCI sustained release layer

\begin{tabular}{|c|c|c|c|c|c|c|c|c|c|}
\hline \multirow{2}{*}{ Ingredients } & \multicolumn{9}{|c|}{ Batch code } \\
\cline { 2 - 11 } & M1 & M2 & M3 & M4 & M5 & M6 & M7 & M8 & M9 \\
\hline MetforminHCl & 500 & 500 & 500 & 500 & 500 & 500 & 500 & 500 & 500 \\
\hline HPMC E15 & 150 & 100 & 50 & 50 & 75 & 100 & 150 & 100 & 50 \\
\hline HPMC K100 & 50 & 100 & 150 & 100 & 75 & 50 & 50 & 100 & 150 \\
\hline Carbopol & - & - & - & 50 & 50 & 50 & 50 & 50 & 50 \\
\hline PVPk30 & 25 & 25 & 25 & 25 & 25 & 25 & 25 & 25 & 25 \\
\hline Sodium Bicarbonate & 50 & 50 & 50 & 50 & 50 & 50 & 50 & 50 & 50 \\
\hline Citric acid & 15 & 15 & 15 & 15 & 15 & 15 & 15 & 15 & 15 \\
\hline MCC & 52 & 52 & 52 & 02 & 02 & 02 & 02 & 02 & 02 \\
\hline Mg. stearate & 5 & 5 & 5 & 5 & 5 & 5 & 5 & 5 & 5 \\
\hline Talc & 3 & 3 & 3 & 3 & 3 & 3 & 3 & 3 & 3 \\
\hline Total & 850 & 850 & 850 & 850 & 850 & 850 & 850 & 850 & 850 \\
\hline
\end{tabular}

Table 2: Evaluation parameters of metforminHCI SR tablets

\begin{tabular}{|c|c|c|c|c|c|}
\hline Formulations & $\begin{array}{c}\text { Friability } \\
(\%)\end{array}$ & $\begin{array}{c}\text { Hardness }(\mathrm{kg} / \mathrm{cm} 2) \\
\mathrm{N}=3\end{array}$ & $\begin{array}{l}\text { Floating lag time } \\
\text { (sec) } N=3\end{array}$ & $\begin{array}{l}\text { Total floating } \\
\text { time* (hrs) }\end{array}$ & $\begin{array}{l}\text { Swelling Index } \\
(\%) \text { after } 10 \text { hrs }\end{array}$ \\
\hline M1 & 0.72 & $7.5 \pm 0.12$ & $30 \pm 3.03$ & $10 \mathrm{hr}$ & 92.2 \\
\hline M2 & 0.54 & $8.1 \pm 0.20$ & $38 \pm 2.24$ & $10 \mathrm{hr}$ & 94.33 \\
\hline M3 & 0.63 & $7.6 \pm 0.18$ & $44 \pm 3.82$ & $10 \mathrm{hr}$ & 96.43 \\
\hline M4 & 0.82 & $7.5 \pm 0.25$ & $55 \pm 2.47$ & $10 \mathrm{hr}$ & 102.7 \\
\hline M5 & 0.64 & $8.0 \pm 0.25$ & $61 \pm 1.85$ & $10 \mathrm{hr}$ & 101.7 \\
\hline M6 & 0.83 & $7.6 \pm 0.25$ & $66 \pm 3.27$ & $10 \mathrm{hr}$ & 99.58 \\
\hline M7 & 0.59 & $8.5 \pm 0.35$ & $68 \pm 2.11$ & $10 \mathrm{hr}$ & 124.8 \\
\hline M8 & 0.79 & $8.4 \pm 0.75$ & $70 \pm 3.51$ & $10 \mathrm{hr}$ & 126.9 \\
\hline M9 & 0.28 & $7.5 \pm 0.52$ & $73 \pm 4.82$ & $10 \mathrm{hr}$ & 127.9 \\
\hline
\end{tabular}

* The study of total floating time was conducted for 10hr only.
All the nine batches were subjected to in-vitro dissolution

Table 3: Formulation table of PioglitazoneHCI IR layer

\begin{tabular}{|c|c|c|c|}
\hline \multirow{2}{*}{ Ingredients } & \multicolumn{3}{|c|}{ Batch Code } \\
\cline { 2 - 4 } & $\mathbf{P 1}$ & $\mathbf{P 2}$ & $\mathbf{P 3}$ \\
\hline PioglitazoneHCl & 15 & 5 & 15 \\
\hline Crosspovidone & 3 & 75 & 7 \\
\hline MCC & 77 & 1 & 73 \\
\hline Mg stearate & 1 & 2 & 1 \\
\hline Talc & 2 & 2 & 2 \\
\hline Color & 2 & $\mathbf{1 0 0}$ & 2 \\
\hline Total & $\mathbf{1 0 0}$ & $\mathbf{1 0 0}$ \\
\hline
\end{tabular}




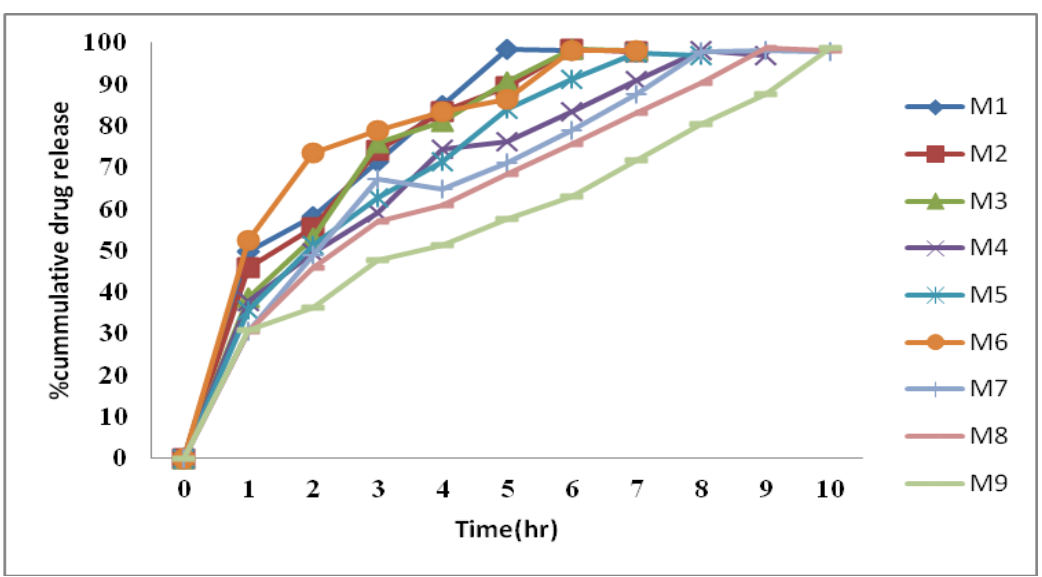

Figure 1 Dissolution comparision of all metformin sustained release tablet

From above all formulations of metformin tablets M9 showing desirable sustained release for 10 hrs so it is concluded as optimized batch.

Table 4: Evaluation parameters of PioglitazoneHCI IR tablets:

\begin{tabular}{|l|l|l|l|}
\hline Formulations & Friability (\%) & $\begin{array}{l}\text { Hardness (kg/cm2) } \\
\mathbf{N}=3\end{array}$ & $\begin{array}{l}\text { DT } \\
\text { (sec) }\end{array}$ \\
\hline P1 & 0.72 & $4.5 \pm 0.10$ & 256 \\
\hline P2 & 0.54 & $5.1 \pm 0.14$ & 260 \\
\hline P3 & 0.63 & $4.6 \pm 0.11$ & 259 \\
\hline
\end{tabular}

For immediate layer of PioglitazoneHCl, we used crospovidone as superdisintegrant. In above formulations P1, P2 and P3 crospovidone was used in concentration of $3 \%, 5 \%$, and $7 \%$ respectively.

From it can be told that formulation P2 and P3 released $85 \%$ of drug within $15 \mathrm{~min}$ which is desirable. Hence Batch P2 with $5 \%$ of crospovidone was optimizesd. Here $5 \%$ of crospovidone was selected because it was recommended by literature \& $7 \%$ crospovidone was rejected.

The drug release data of MetforminHCl and Pioglitazone $\mathrm{HCl}$ were fitted to models representing zero order, first order, Higuchi's and Korsmeyer's equation ${ }^{9}$ kinetics to know the release mechanisms. The data were processed for regression analysis using MS EXCEL 2007 statistical function. The results are shown in Table 5 .

In the present study, in vitro release profiles could be best expressed by Higuchi's equation as optimized formulation (M9P2) showed good linearity $\left(\mathrm{R}^{2}: 0.975\right)$ indicates that diffusion is dominant mechanism of drug release with this formulation $^{4,5}$.
After evaluating all the batches M9P2 is optimized and so final formulation of bilayer tablet is given in table 7 and its evaluation date is given in table 8 .

Table 6: Formulation of Final optimized batch M9P2

\begin{tabular}{|c|c|c|}
\hline Ingredients & \multicolumn{2}{|c|}{ Final Batch (mg) } \\
\hline PioglitazoneHCl & 15 & \multirow{6}{*}{$\begin{array}{l}\text { Immediate } \\
\text { release layer }\end{array}$} \\
\hline Crosspovidone & 3 & \\
\hline $\mathrm{MCC}$ & 77 & \\
\hline Mg stearate & 1 & \\
\hline Talc & 2 & \\
\hline Color & 2 & \\
\hline MetforminHCl & 500 & \multirow{11}{*}{$\begin{array}{c}\text { Sustained } \\
\text { release layer }\end{array}$} \\
\hline HPMC E15 & 50 & \\
\hline HPMC K100 & 150 & \\
\hline Carbopol & 50 & \\
\hline PVPk30 & 25 & \\
\hline Sodium Bicarbonate & 50 & \\
\hline Citric acid & 15 & \\
\hline $\mathrm{MCC}$ & 02 & \\
\hline Mg. stearate & 5 & \\
\hline Talc & 3 & \\
\hline Total & 950 & \\
\hline
\end{tabular}

Table 5: Analysis of Release Mechanism MetforminHCl of Optimized Batch M12P2

\begin{tabular}{|c|c|c|c|c|c|}
\hline \multirow{2}{*}{$\begin{array}{l}\text { Formulation } \\
\text { (M12P2) }\end{array}$} & \multirow{2}{*}{$\begin{array}{c}\text { Zero order } \\
\mathbf{R}^{\mathbf{2}}\end{array}$} & \multirow{2}{*}{$\begin{array}{c}\text { First order } \\
\mathbf{R}^{2}\end{array}$} & \multirow{2}{*}{$\begin{array}{l}\text { Higuchi } \\
\mathbf{R}^{2}\end{array}$} & \multicolumn{2}{|c|}{ Korsmayer Peppas } \\
\hline & & & & $\mathbf{R}^{2}$ & $\mathbf{n}$ \\
\hline MetforminHCl & 0.951 & 0.780 & 0.975 & 0.96 & 0.502 \\
\hline
\end{tabular}




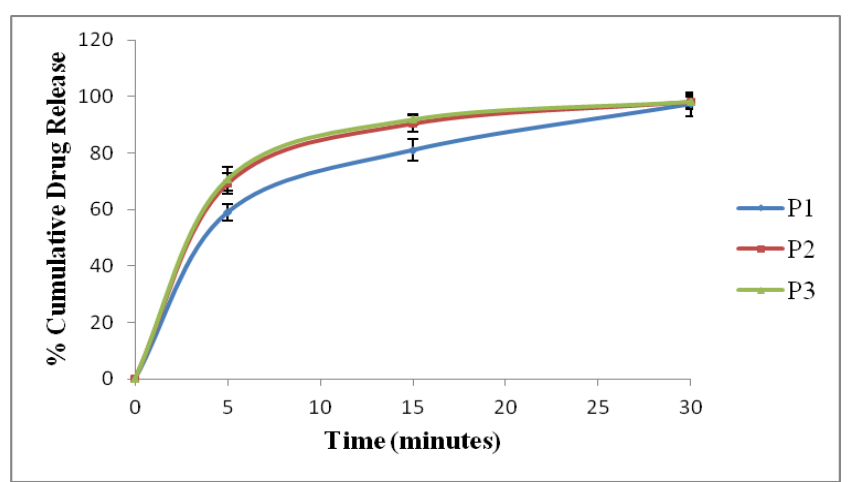

Figure 2: Dissolution comparision of all pioglitazoneHCl IR tablets

Table 7: All data of optimized batch

\begin{tabular}{|l|l|l|}
\hline Parameters & M9 & P2 \\
\hline Friability(\%) & 0.28 & 0.54 \\
\hline Hardness(kg/cm2) (n=3) & $7.5 \pm 0.52$ & $5.1 \pm 0.14$ \\
\hline Desintegration time(sec) & - & 260 \\
\hline Floating lag time (sec) (n=3) & $73 \pm 4.82$ & - \\
\hline Total floating time (hrs) & 10 & - \\
\hline Swelling index(\%)after 10 hrs & 127.9 & - \\
\hline Kinetic(value) & Higuchi & - \\
\hline \multicolumn{2}{|l|}{} \\
\hline Drug release & $\mathrm{r}^{2}=0.975$ & \\
\hline After 30 min & - & $98.10 \pm 1.67$ \\
\hline After 10hr & $-98.82 \pm 3.75$ & - \\
\hline
\end{tabular}

\section{CONCLUSION:}

HPMCE15, HPMCK100 and carbopo1934P were used as matrix forming polymer for the preparation of MetforminHCl sustained release layer which enabled drug release from 5 to $10 \mathrm{hrs}$ in different proportion of matrix polymers with near to zero order release profile and diffusion as preliminary release mechanism. Pioglitazone $\mathrm{HCl}$ immediate release layer was prepared using crosspovidone in different proportion where $3 \%$ was found promising which disintegrates completely within $4 \mathrm{~min}$. The core tablet of MetforminHCl in bilayered tablet was prepared by wet granulation and immediate release layer of Pioglitazone $\mathrm{HCl}$ was compression coated on it. The optimized bilayered tablet can be used as combination therapy for diabetes which reduses dosing frequency and improves patient compliance. Pioglitazone release shows that the dissolution rate of Pioglitazone can be enhanced considerably by using crosspovidone as super disintegrent.

SR fixed dose bilayer matrix tablets containing $500 \mathrm{mgMetforminHCl}$ as SR from one layer and $15 \mathrm{mg}$ Piogleitazone as from another layer can be successfully formulated.

\section{ACKNOWLEDGEMENT:}

The authors acknowledge Bharat Parenterals Ltd, Baroda, India.for providing gift sample of MetforminHCl and PioglitazoneHCl.

\section{REFERENCES:}

1. Schwartz S, Fonseca V, Berner B, Cramer M, Chiang YK, Lewin A: Efficacy, tolerability, and safety of a novel once-daily extended-release Metformin in patients with type 2 diabetes. Diabetes Care 29:759 -764, 2006.

2. Dunn C J, Peters DH. Metformin: A review of its pharmacological properties and therapeutic use in non-insulin dependent diabetes mellitus. Drugs. 1995; 49:721-749.

3. Gangji AS, Cukierman T, Gerstein HC, Goldsmith $\mathrm{CH}$, Clase CM: A systematic review and meta-analysis of hypoglycemia and cardiovascular events: a comparison of glyburide with other secretagogues and with insulin. Diabetes Care 30: 389-394, 2007.

4. Fassihi RA, Ritschel WA. Multiple layer, direct-compression controlled-release system: In vitro and in vivo evaluation. J. Pharm Sci. 1993; 82: 750-754.

5. Peppas NA. Analysis of Fickian and non-Fickian drug release from polymers. Pharm. ActaHelv. 1985; 60: 110-111.

6. Enose AA, Prithiviraj A, Kesavan B, and et al. Eudragit NE30D based metformin gliclazide extended release tablets: formulation, characterization and in vitro release studies $[\mathrm{J}]$. Chem. Pharm Bull, 2002, 50 (11), 1495-1498.

7. Defang O, Shufang N, Wei L. In vitro and in vivo evaluation of two extended release preparations of combination metformin and glipizide. Drug Dev. Ind. Pharm. 2005; 31: 677-685.

8. Scheen AJ. Clinical pharmacokinetics of metformin. Clin. Pharmacokinet. 1996; 30: 359-371.

9. Korsmeyer RW, Gurny R, Doelker E. Mechanism of solute release from porous hydrophilic polymers. International journal of Pharmaceutical sciences. 1983; 15: 25-35. 